\title{
BILATERAL BIFID MANDIBULAR CONDYLE WITH TEMPORO-MANDIBULAR JOINT ANKYLOSIS
}

Amit Nandan Dhar Dwivedi ${ }^{1}$, Ramchandra Shukla ${ }^{2}$, Arvind Srivastava ${ }^{3}$, Suchi Tripathi ${ }^{4}$

\section{HOW TO CITE THIS ARTICLE:}

Amit Nandan Dhar Dwivedi, Ramchandra Shukla, Arvind Srivastava, Suchi Tripathi. "Bilateral bifid Mandibular Condyle with Temporo-Mandibular Joint Ankylosis". Journal of Evolution of Medical and Dental Sciences 2014; Vol. 3, Issue 25, June 23; Page: 6864-6869, DOI: 10.14260/jemds/2014/2829

\begin{abstract}
We report a case of 10years old female child who presented with presenting complaints of progressive difficulty in jaw opening. The parents gave history of facial trauma suffered five years back. A radiograph obtained at that time was unremarkable. This time she was advised computed tomography (CT) examination of temporo-mandibular joint (TMJ) to evaluate the severity and extent of ankylosis. Examination was done on a 64 slice CT scanner (GE) with isotropic images and additional volume rendered and multiplanar acquisitions. Findings were suggestive of bilateral mediolateral bifid mandibular condyles with fibrous, partial bony ankylosis. Both mandibular condylar head were enlarged with abnormal contour. Condyles were bifid separated by a distinct groove.
\end{abstract}

KEYWORDS: Bifid mandibular condyles (BMC), temporo-mandibular joint ankylosis(TMJA).

INTRODUCTION: Bifid mandibular condyle (BMC) is a rare condition ${ }^{[1]}$ and usually has no significant complaints or clinical features, such as pain or restricted movements.[2] Although this type of morphological change is generally associated with trauma, ${ }^{[3]}$ conditions, such as teratogenic drug use, genetic inheritance, infection and exposure to radiation can also cause the development of this anomaly. Temporomandibular joint (TMJ) ankylosis is a pathological change with bony or fibrous ankylosis with deformity of the articular fossa and mild or severe formation of osseous tissue, impairing functions, such as speech, chewing and mouth opening.[4] This condition could be consequence of trauma, infection or degenerative changes. When ankylosis occurs during the childhood, the patient could show severe facial alterations. According to the reviewed literature, facial trauma in early stages of facial development is the most important etiologic factor of this pathology.[5-8]

There are very few reports of bilateral bifid mandibular condyle (BMC) and its association with temporomandibular joint ankylosis(TMJA). BMC associated with temporomandibular joint ankylosis (TMJA) is an extremely rare abnormality. This is a poorly understood condition with regard to aetiology, clinical implications and morphology. An extensive search revealed only four cases of BMC with TMJA reported in the English medical literature. ${ }^{[9-12]}$ The use of 64 slice CT with its isotropic images in all three planes along with volume rendering and multiplanar capabilities evaluates the structural abnormality in its totality.

CASE HISTORY: A ten years old female child presented with progressive difficulty in mouth opening and chewing. She suffered trivial facial trauma five years ago. She had no complaints at that time and radiographs as told by parents were unremarkable. Her complaints started after a year and as noticed by the parents during the time of feeds. Her condition worsened over the years. This time she was referred for CT evaluation for extent and severity of temporomandibular joint ankylosis (TMJA). 
Both mandibular condylar head were enlarged, showed abnormal contour, mushroom shaped with bifid condyles separated by a distinct groove (Fig. 1, 2). Medial condylar head was seen articulating with the temporal fossa (Fig 3). The lateral head on both sides show features of ankylosis with markedly reduced joint space, irregular joint margins, soft tissue and bony debris bridging the joint surface (Fig 4). Subchondral sclerosis was noted involving both articular margins.

Features were suggestive of bilateral mediolateral bifid mandibular condyles with fibrous and partial bony ankylosis. Images acquired in all three planes and additional volume rendered images highlights the use of 64 slice CT in defining this rare entity.

DISCUSSION: According to Blackwood,[7] two articulating surfaces of the BMC are divided by a groove and can be orientated mediolaterally or anteroposteriorly, characterizing a specific entity. In this case report, as postulated above, groove formation and presence of medial and lateral head of the left condyle clearly demonstrated the formation of the BMC bilaterally as seen in Fig $(1,2)$.

Although TMJ ankylosis has clinical symptoms, such as pain, limitation of mouth opening and asymmetry with mandible and chin deviation, ${ }^{[13]}$ due to its minimal symptomatology, BMC remains a relatively uncommon entity. In view of this, BMC diagnosis usually relies on radiological rather than clinical evidence. It is usually identified as an incidental finding on panoramic radiographs and thus these findings are exceptional in human remains and living population.

This case report illustrates the need for accurate examination of patients with unexplained temporomandibular joint ankylosis. According to Linnau et al,[14] a simple clinical evaluation does not fully characterize facial fractures or deformities, and the deeper mid face is not accessible to physical examination. The association between BMC and TMJ ankylosis is rare and must be carefully evaluated. The progress of diagnostic imaging has included the development and improvement of new imaging techniques that allow easier and earlier detection of pathological changes that could be extremely hazardous to the patient.[5]

In this field, advances in radiographic modalities and imaging methods have led to various options for visualizing the TMJ. This case report highlights the use of 3D-CT reconstructed images (Fig. 1-4), enabling the radiologist to visualize and manipulate the image data quickly to get a better visualization of the condyle and its relationship with base of the skull and surrounding structures. Thus, more details were obtained from the images regarding normal and pathological tissues.[15]

Additionally, the use of axial and MPR-CT images improved the capacity of the radiologist in determining the actual situation of pathologic tissues and the true extension of the lesions.

CONCLUSION: This case report helps to elucidate the CT morphology of bifid condyles in cases of BMC associated with TMJA. Further studies with imaging performed at earlier stages of development of the BMC and comparing the relative evolution of the double heads and ankylosis would shed more light on the role of bifidity of the condyle in progressing into TMJ ankylosis. 


\section{REFERENCES:}

1. Gundlach KK, Fuhrmann A, Beckmann-Van der Ven G. The double headed mandibular condyle. Oral Surg Oral Med OralPathol 1987; 64: 249-253.

2. Hersek N, Ozbek M, Tasar F, Akpinar E, Firat M. Bifid mandibular condyle: a case report. Dent Traumatol 2004; 20: 184-186.

3. Stadnicki G. Congenital double condyle of the mandible causing temporomandibular joint ankylosis: report of case. J Oral Surg 1971; 29: 208-211.

4. Manganello-Souza LC, Mariani PB. Temporomandibular joint ankylosis: report of 14 cases. Int J Oral Maxillofac Surg 2003; 32: 24-29.

5. Remi M, Christine MC, Gael P, Soizick P, Joseph-Andre J. Mandibular fractures in children: long term results. Int J Pediatr Otorhinolaryngol 2003; 67: 25-30.

6. Toyama M, Kurita K, Koga K, Ogi N. Ankylosis of the temporomandibular joint developing shortly after multiple facial fractures. Int J Oral Maxillofac Surg 2003; 32: 360-362.

7. Blackwood HJ. The double-headed mandibular condyle. Am J Phys Anthropol 1957; 15: 1-8.

8. Eckelt U, Hlawitschka M. Clinical and radiological evaluation following surgical treatment of condylar neck fractures with lag screws. J Craniomaxillofac Surg 1999; 27: 235-242.9.

9. To EW. Mandibular ankylosis associated with a bifid condyle. J Craniomaxillofac Surg 1989; 17: 326-328.

10. Daniels JS, Ali I. Post-traumatic bifid condyle associated with temporomandibular joint ankylosis: report of a case and review of literature. Oral Surg Oral Med Oral Pathol Oral Radiol Endod 2005; 99: 682-688.

11. Sales MAO, Oliveira JX, Cavalcanti MGP. Computed tomography imaging findings of simultaneous bifid mandibular condyle and temporomandibular joint ankylosis: case report. Braz Dent J 2007; 18: 74-77.

12. Guven 0. A clinical study on temporomandibular joint ankylosis. Auris Nasus Larynx 2000; 27: 2733.

13. Linnau KF, Stanley RB Jr., Hallam DK, Gross JA, Mann FA. Imaging of high-energy midfacial trauma: what the surgeon needs to know. Eur J Radiol 2003; 48: 17-32.

14. Santos DT, Cavalcanti MGP. Osteosarcoma of the temporomandibular Joint: report of 2 cases. Oral Surg Oral Med Oral Pathol Oral Radiol Endod 2002; 94: 641-647. 


\section{CASE REPORT}

Figure 1: Volume rendered image (Surface Shaded display, CT) showing a distinct groove on the left side (arrow):

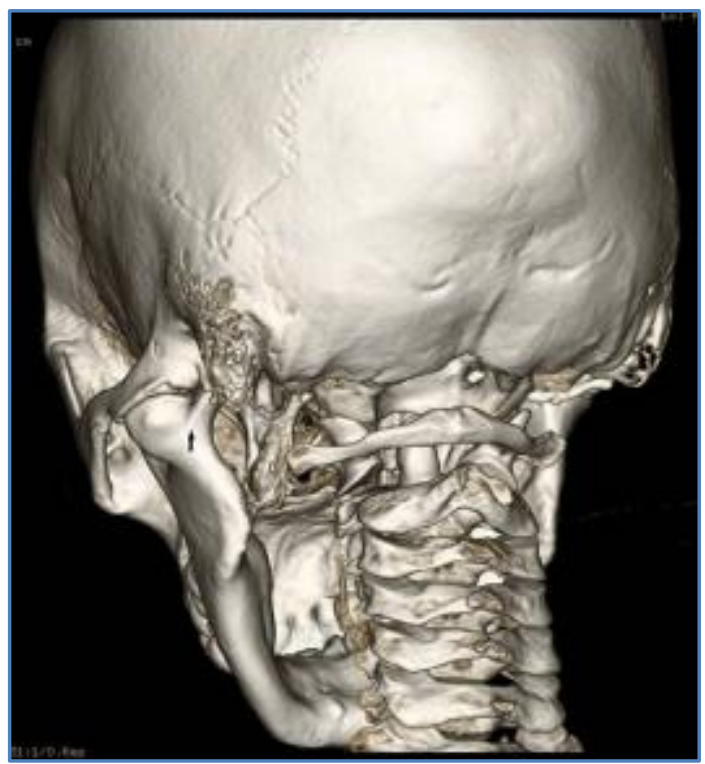

Figure 1

Figure 2: Volume rendered image (Surface shaded display, CT) showing a similar groove on the right side (arrow):

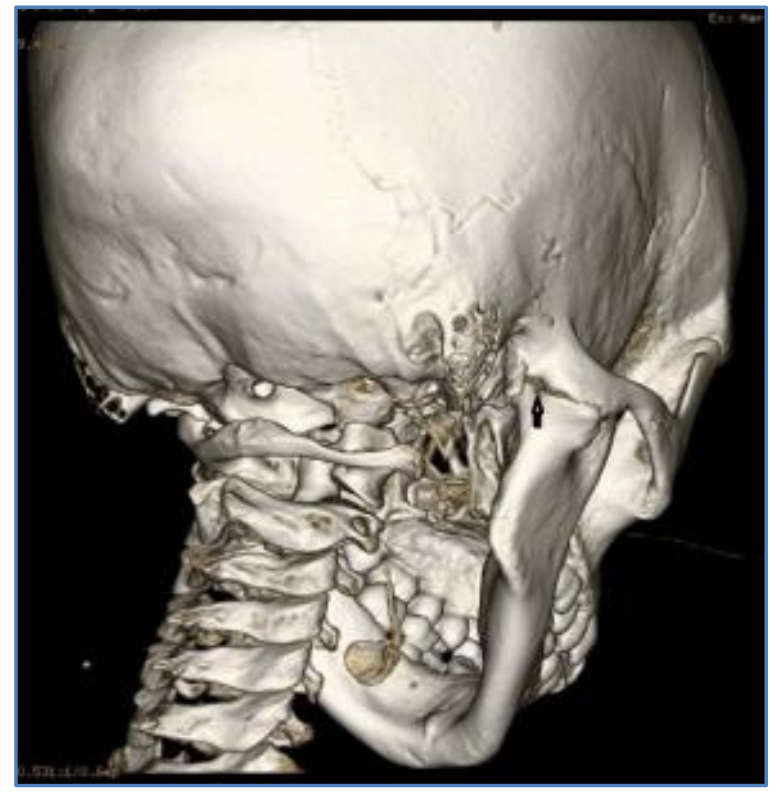

Figure 2 


\section{CASE REPORT}

Figure 3: Coronal reconstructed image (multidetector CT scan) showing medial condylar head articulating with the temporal fossa bilaterally (black arrows):

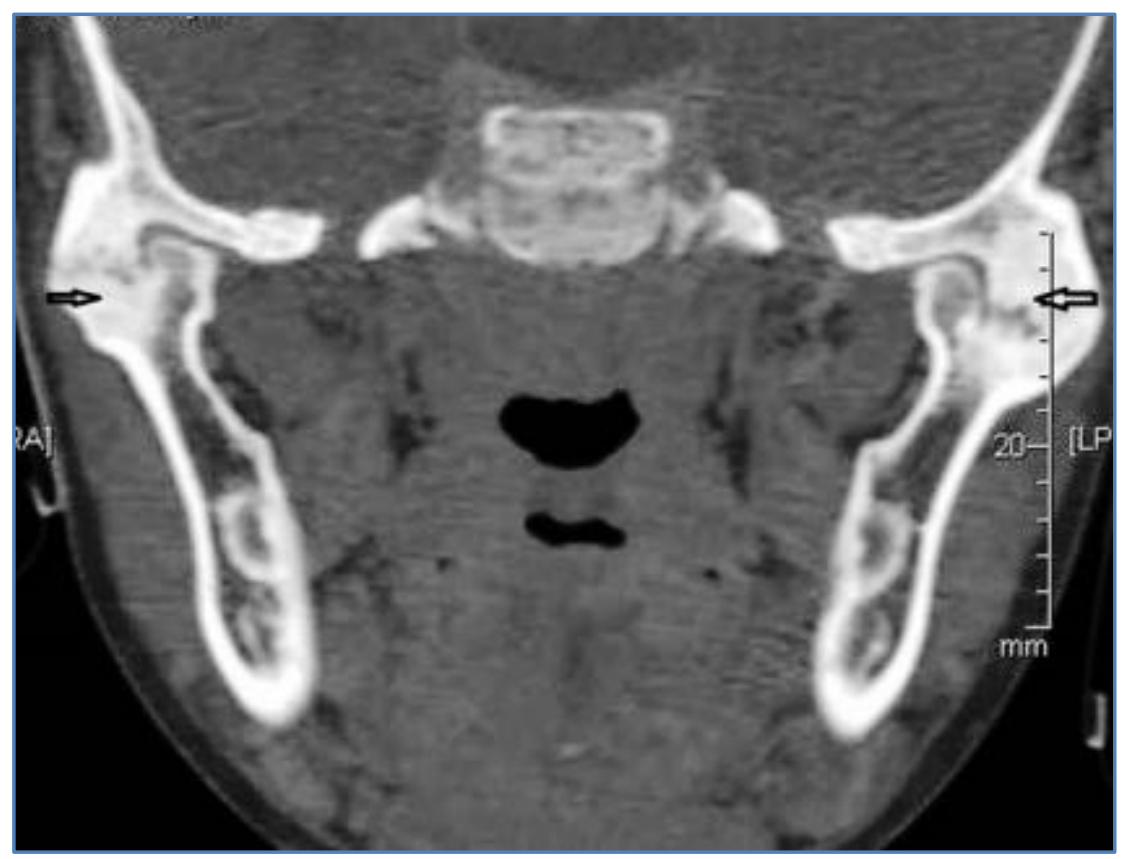

\section{Figure 3}

Figure 4: Coronal reconstructed image(multidetector CT scan) showing lateral head on both sides with features of ankylosis and markedly reduced joint space and irregular joint margins bilaterally(black arrows):

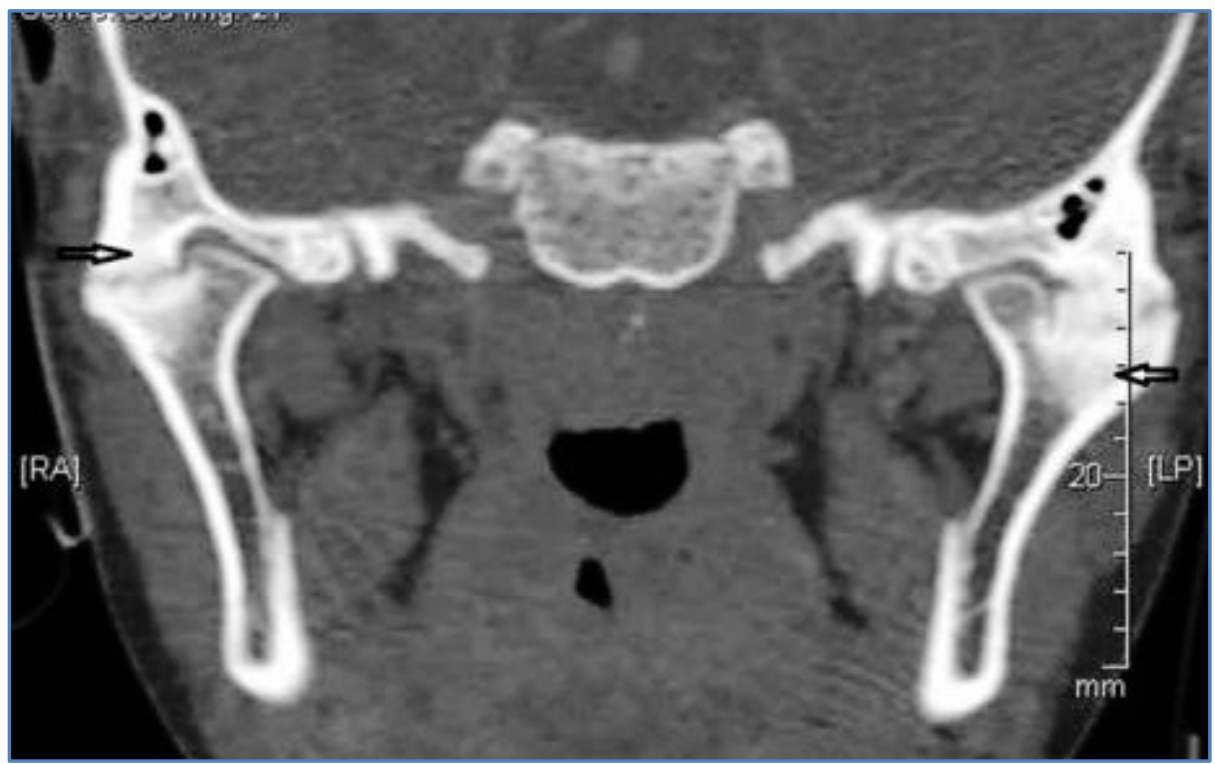

Figure 4 


\section{CASE REPORT}

\section{AUTHORS:}

1. Amit Nandan Dhar Dwivedi

2. Ramchandra Shukla

3. Arvind Srivastava

4. Suchi Tripathi

\section{PARTICULARS OF CONTRIBUTORS:}

1. Assistant Professor, Department of Radiodiagnosis and Imaging, Institute of Medical Sciences, Banaras Hindu University.

2. Professor, Department of Radiodiagnosis and Imaging, Institute of Medical Sciences, Banaras Hindu University.

3. Professor, Department of Radiodiagnosis and Imaging, Institute of Medical Sciences, Banaras Hindu University.

4. Resident, Department of Internal Medicine, Institute of Medical Sciences, Banaras Hindu University.

\section{NAME ADDRESS EMAIL ID OF THE} CORRESPONDING AUTHOR:

Dr. Amit Nandan Dhar Dwivedi, Department of Radiodiagnosis and Imaging, Institute of Medical Sciences,

Banaras Hindu University,

Varanasi-221005

Email: amitnandan21@yahoo.com

Date of Submission: 24/05/2014.

Date of Peer Review: 26/05/2014.

Date of Acceptance: 10/06/2014.

Date of Publishing: 17/06/2014. 